\title{
Challenges of the implementation of Integrated Functional Adult Education (IFAE) in Ethiopia: A case of Oromiya National Regional State
}

\section{Tolera Negassa}

College of Education and Behavioral Science, Arsi University, Ethiopia.

Accepted 24 July, 2019

\begin{abstract}
The purpose of this study was to demonstrate the challenges of the implementation of Integrated Functional Adult Education (IFAE) in the Oromiya National Regional State. This study employed a qualitative study and few quantitative data type. The qualitative data was collected from participants of regional education office, district education office heads, experts at different education offices, facilitators of the adult literacy program and adult literacy learners through the interview, literacy classroom observation and FGD methods. The study used a purposive sampling method to include participant. After collecting the data, qualitative data processing was made (editing, classification, and thematic formation). The interpretation is a narrative analysis of relevant incident of the respondents' responses. The results reveal that the program implementation is hampered by access to adults learning the program, lack of organized structure, coordination, and commitment to improving the IFAE program. The literacy classroom observation results reveal that some of the contents like counting and adding numbers are more liked by participants. On the other hand, writing names, constructing words and sentences found to be a challenge for the learners. The curriculum is not implemented as it was stipulated in the textbook of the learners, only literacy facilitators in the form of intergenerational learning modality run the program, without the involvement of the agriculture and health extension facilitators. The study result shows that the current model, used to implement IFAE, could not bring a change as the right way to escape from illiteracy problem. In the region, despite the growth of formal education, adult education has been impeded and the program handling system becomes at the verge of dying. Hence, the government has to restructure the fragmented system of the program that could minimize the gap between the policy implementers and the end users.
\end{abstract}

Keywords: Literacy, functional adult education, non-formal education, multi-sectoral model.

\section{INTRODUCTION}

The practical implementation of adult education assumes that administrators at various levels have to interpret the expectations of policymakers by generating rules and regulations that can support the practices. Apart from the bureaucratic functions at different levels, teachers/facilitators eventually have to translate the rules and regulation into actual classroom practice on a day-today basis (McGinn and Street, 1982). In this regards, adult learning policy is complex, since it makes important contributions to many other policies (e.g. economy, health, family, etc.). The responsibility for adult learning policy is often divided across several ministries and agencies (e.g. education, agriculture, health, business, etc.) and several levels of the policy are implemented with local institutions such as facilitators, schools, local administrators, and districts education offices, region, and nation. European Commission (2015) noted that shared responsibility among stakeholder often results in a 
situation where the adult learning policy is fragmented and its efficiency suffers from insufficient coordination.

Moreover, the forces such as the management styles, organizational structure, legitimate authority structures within a given system, and the micro-political processes provide the milieu for policy re-contextualization (Welsh and McGinn, 1999). A study conducted by Van Horn and Van Meter (1977) has come up with some general explanations for unsuccessful implementation of programs: clarity of the communication process, capability or ability at all levels, shortage of resources, and failure of policymakers to implement their own assignments. In Ethiopia, since 1967, adult and nonformal education (ANFE) has been practiced in slow motion, and suffered from several factors (Workineh, 1991). In a similar way, Mohammed (2016) asserted that IFAE implementation was challenged by a lack of regular meeting, poor quality of training given for facilitators and the shortage of resources. Consistent with these other studies, found that Integrated Functional Adult Education (IFAE) implementation was challenged by poor institutionalization, integration, and coordination (Chamebo, 2016; Sisay and Yilfashewa, 2017). These studies were based on limited context (facilitators and adult learners opinion) and did not cover the involvements of responsible stakeholders running the program at different levels such as the bureau heads, experts, focal person and school committee. Moreover, the variables did not address varieties of issues that influence the implementation of ANFE. These situations has made to think the research gap in the current study focusing on the data of responsible stakeholders at different levels, experts, facilitators, focal persons, and adult learners to address the problems; the variables of the study extracted from field result are problems of access to the literacy program, structural issue, coordination at a higher level down to the local, attitude, and ability of facilitators are among others.

The Integrated Functional Adult Education (IFAE) delivery mode, which is a multi-sectoral model under the umbrella of shared responsibilities of different sectors (e.g., education, agriculture, health, business, etc.) could not show the required change. The implementation practices are inadequate to lead to better results from year to year. Some leaders were deceived by the false report/feedbacks obtained in the program at different levels of education sectors, as a result, they could not help educational leaders, researchers, and practitioners understand whether or not the program failed or successful. Therefore, the current study result gives opportunity for researchers, policymakers, leaders, experts, and practitioners had better understand the implementation of this particular educational program (IFAE) in the specific contexts of adult literacy learners. To this end, the study has addressed the following basic research questions:

- What are the major challenges of implementing integrated functional adult education in the regional state?

- What are the possible ways to overcome the challenge faced in implementing integrated functional adult education in the regional state?

\section{METHODOLOGY}

\section{Research design}

This research employed qualitative design substantiated by some quantitative data. The qualitative design drew on describing the implementation of IFAE from the perspectives of leaders, coordinators, experts, adult learners, and facilitators. As Creswell (2007) says, a qualitative research design helps to interpret and make a better understanding of the multifaceted reality of a given situation. The objective of describing people's experience in a given situation better achieved with this method than the quantitative method. Besides, the researcher utilized and analyzed samples of quantitative data documented from government report so as to complement data collected from the field.

\section{Sample and sampling technique}

In this study, key informants were involved by virtue of their positions and influence activities of the IFAE program through their decision. Yin (2011), says, in qualitative research, key informants are those who have positions in a research setting that give them specialist knowledge about happenings, which are more extensive, detailed or privileged than ordinary people. The informants of this research were the one, who runs the IFAE program under their leadership and the system itself. The researcher assumes that it is possible to get detail information from these key informants than collecting data from people indirectly involved to run the program such as health and agriculture development agents.

Accordingly, the researcher used a purposive sampling technique to collect data from the participants. The data was collected from 39 respondents (3 education bureau heads, 7 experts, 12 facilitators, 8 adult education coordinators, and 9 adult learners). The selection of experts, facilitators, coordinators, and adult learners was made based on their experience, active involvement in running adult education program at different levels and training centers, and the adult learners were selected from round II by observing their classroom performance and in consulting their facilitators.

\section{Data collection methods}

The study employed an interview and Focus Group 
Discussion (FGD) guide semi -structured questions. The semi-structured qualitative study is used here to refer to qualitative approaches, typically involving interviews and, interactive responses of the respondents. The questions were about the challenges and failure stories of integrated functional adult education program, practices and its setbacks, the availability of resources (human, materials, and finance) and the future direction of the program. Besides, the probing question derived from participates responses were also used. In addition to these, three times actual literacy classroom observation was used as supplementary evidence for the actual practices in the teaching-learning process.

\section{Validity and reliability of data}

In this study, data validation was done all the way through the data analysis process. The researcher stayed with key informants and FDGs on average 1:30 hrs. Selecting a convenient time usually morning time, and separate space from their offices were used. The interpretation bias was controlled through listening to recorded interviews, FGD documents, and transcribing Afan Oromo language into the English language. In fact, the researcher collected feedback on the themes, method, and results from three (3) readers; 2 from home university and one (1) from other university who had rich research experiences and qualified in the area. The experts are commented on the validity in terms of its objectives, methods, genuinely collected field reports and its organization. The reliability of the themes was assessed based on the agreement of the three readers and the extent to which the themes address the right opinion of the participants. To increase the consistency and reliability of the method, the researcher documented all procedures and set up a detailed protocol for the analysis. Moreover, the data were collected from multiple sources such as a regional level deputy head, districts education offices head down to Kebele local adult learners.

\section{Data analysis}

Data for the research were qualitatively collected with the support of interview and focus group discussions. After field, the largely unstructured data was reorganized through transcribing local language (Afan Oromo) into English language data. This was made by going back to the research questions, then organizing the collected data for analysis and interpretation based on a predetermined series of a semi-structured interview and guide questions for focus group discussions. The analysis involved a method that consists of several stages such as familiarization, identifying a thematic framework and interpretation. The analysis involved direct quotations and paraphrase of stories presented by respondents. Key informants and FGD participants taking into account the context of each case and the different experiences of each respondent. This is beyond a naturally occurring talk with the respondents and writes text.

To supplement qualitative data results, quantitative data showing some gap between planned, enrollment and completers of IFAE participants of Arsi and East Showa Zones were analyzed using percentage and presented by graphs. In all cases, the key issues were specifically focused on the implementation of IFAE policy, and strategy, which were revealed in practices, and the challenge faced in Oromiya National Regional State as understood by officials, experts, focal persons/coordinators, and facilitators.

\section{RESULTS}

Like formal education, non-formal education has a number of drawbacks in addressing its mission and vision. The circumstance under which the non-formal education for adults operates seems mostly not structured, planned and organized as a condition in the formal program. Apart from some achievements, it is quit imperative to look into the challenges of adult education. In this study, the research question framed earlier has helped much to analyze some major challenges that hindered IFAE program implementation. The participants at different levels have noted some of the challenges in implementing an integrated functional adult education program. The challenges are identified as lack of access to literacy, structure, coordination, capability, planning and attitudinal challenges.

\section{Access to literacy program}

The high-level access to literacy in the adult population improves adult literacy rates that can have effects in creating a base for economic development, social, and political participation.

In the regional state under study, the two-year IFAE program for 15 to 60 year-olds was assumed to provide mother tongue reading, writing and arithmetic skills development integrated with practical knowledge and skills. However, the accessibility of the program in the regional state is seriously impaired by different factors as elaborated by different participants of the study.

In order to answer the question that goes like "What are the access to integrated functional adult education program in the regional state?"The bureau head began by describing difficulties in providing adult education.

... Integrated Functional Adult Education (IFAE) has given a chance for people who could not 
follow their education in formal education at formal schools. To this end, a strategy was set in 2008 at the national level. We adopted the strategy in 2009 and used in $2010-2017$ at the regional level. Since then, out of 9million people who cannot read and write we have trained and certified only 1.8 Million people. The respondent said, I, assume the majority of the trained adults have the skills of reading, writing and conducting arithmetic. However, there were no tracer studies conducted as to whether or not the trained adults continued to use their literacy skills. The majority may be relapsed into illiteracy because of lack of follow-up and continuity of the program after round II completion (Key Informant 1, 11th Jan 2017).

On the set of participants' responses above, it could be plain that adult education had better performances in helping some adults to stimulate their needs based on strategies set. The region has reached only $20 \%$ of the 9 million in almost in a decade. After completing round I and round II training, the participants of the adult literacy program has the opportunity to join grade five formal education as stipulated in the strategy. The endeavor itself has not been simple, however, the government did not make an attempt to supervised periodically the program based on its' rounds to meet the demands of adult learners. The participant said, "no tracer studies made as to whether the knowledge and skills acquired by the learners are benefiting them on their day-to-day activities". Besides, there is no data at hand regarding the number of young adults who got the opportunity to join formal education. In this regard, having a well-defined policy and strategy by itself cannot end the problems, unless the implementers show commitment and accountable to the program. The reference 1.8 million made seems only for the report to the top-management, and the situation at local community may not reveal the reality and the impact of IFEA training on the community of practices was not being emphasized.

In relation to program development, the deputy head at East Showa Education Office replied that:

...the development of adult education could be traced back to the previous regime (Derge regime), and pass through a number of challenges. Currently, access to education is not a big deal in the Zones and in my Districts. In all our Districts, each Kebele has at least one primary school. In some rural kebeles, very few schools are used as adult training centers to run IFAE program. At schools and other training centers, the program was not consistent in enrolment and training; collecting feedbacks from trainees as to whether the program benefited them. Regarding attendance, we plan a high number and dropouts high number as well (Key Informant 2, 13th Jan 2017).

In this quoted response, the participants remembered that adult education has got much emphasis in the time of Derge regime where the program was implemented in the form of a campaign under the leadership of Ministry of Education. During that time, adult education has been highly structured, instruction-based, and order-driven prescriptive. The need is rather from the government side and was not from the side of adults. The role of the facilitators was highly focusing on equipping adults in literacy and numeracy skills. The program was coordinated by volunteer service students from universities and high schools. The impact of the campaign has made the literacy number raise from 20 to $52 \%$. After the regime change in 1994, the issue of adult education was dropped from the government agenda until 2004. However, adult and non-formal education program latter included in the Education Sector Development Program III in 2005. The Ministry of Education for two decades did not give attention to the program that has influenced the regional state to implement IFAE program poorly. Even in the current condition, the government has given much emphasis on child education and opened schools at each Kebele level. The respondent is also much concerned about the difference between enrolment, attendants and completers that significantly affect the program. One can imagine that since the main stakeholders like the $\mathrm{MoE}$, the regional government, and the districts are not much concerned about the program, an adult learner who looks forward to demand-driven learning opportunity could not have the audacity and determination to visit training centers for learning.

At the local level, the adult education coordinators are responsible to plan, follow up and coordinate the activities of training centers. It was believed that their efforts have brought very few impacts on the program. In this regard, Arsi Zone adult education coordinator said:

...the Zone hasover 1000 training centers; high number of enrolment at different centers and employed facilitators at Kebele level. For example, in the last three years (2015-2017) we have trainedover 500 people. Among these, some of the participants(young age)were moved to formal school or joined regular program. In most of the training centers, the learners are attending their trainings under shad and at households apart from some formal schools, which indicated needsin adult literacy program. However, wehave problems of coordination, planning and follow-up among sectors. The literacy, health, business and agriculturefacilitators run their training in separate time and days. In the majority of rural kebeles, literacy facilitators run the program alone as a result; adult learners are not acquiring knowledge from the package of IFAE program as per the strategy (Adult 
education coordinator, 11th Jan 2017).

The informant reflected that in Arsi zone the number of participants in the adult literacy program reduced by $50 \%$ after enrolment. As a positive impact of the program, some adult literacy program attendants move or got the opportunity to join formal education after completing Roundl and Round II trainings. This condition can have significant impact on IFEA training, but from field observation at some training centers, the facilitators use intergenerational teaching model. In this model, young children are attending literacy class with older adults. In fact, young children who supposed to attend formal school are attending the program. This shall not be a surprise since some of them may not be an adult. Apart from offering training at schools, adults are attending IFAE program under shade, religious institutions, and at household level. In this regard, learning might be affected by the classroom learning condition such as the sitting arrangements, attention-diverting rooms and underutilization of teaching resources. It is also difficult to associate the reality of classrooms motivation, attention, active participation, and group discussions withdelivery of lessons at household level.Moreover, the zone has the problem of coordination among the different sectors, which affect team spirit and resulted in having fractured goal. The education sector by their virtue of coordination in formal education mandated to coordinate the program. Nevertheless, other sectors such as agriculture, health and business are not involved in coordinating, proper lesson delivery and other activities of IFAE.

The researcher further extended the issue to the literacy participant to narrate the challenges they came across through literacy program. The participants were in Round II literacy attendants at Japa Primary School in Adama City administration. The facilitator conduct intergenerational class, meaning adults mixed with children. For the purpose of this study, the researcher did not included children in the FGD.In this regards, majority of the participants in the FGD have said that,

.... head of joining the program we did not have the skills of reading, writing, and arithmetic but after attending the IFAE training we have the skills of reading, writing names, and some texts in our mobile phone and numbers. We assumed that we had an opportunity to see the importance of education in solving some of our problems. However, the center has no learning facilities, coordination, and commitment to attendance and sometimes could not come to the class because of our personal problem at home. Majority of us not able to master writing letters in its alphabetical order and the arithmetic part particularly, subtraction, multiplication and division are also not well captured. Some participants said that our preference is more on developing arithmetic skills because we frequently use them when call dial and for market purpose (FGA1, Feb 12, 2017).

The FGD discussants have depictedabout the benefits and challenges of IFAE, and further noted about the practices of intergenerational learning or children attending literacy class with their parents as a challenge. The adults have different needs in developing literacy skills than children to facilitate their daily activities such as abilities of using letters and numbers for their mobile, writing names and addresses of their friends and children. Some of the children are attending formal school but use IFAE class to strength their skills particularly in local language "Afan Oromo." In this regard, the researcher observed that some participants are comfortable to setwith children and ready to learn from one other assuming that knowledge is co-created and shared among people. Whereas, others prefer to set alone particularly some children are not supportive to the adults. The children want to complete the tasks given in due time because adults are not in their pace. There is a big mismatch of ability difference in responding questions presented from the facilitator, which could be attributed to age and experience as a factor for learning. Apart from these, the attendants have indicated about the problem of weak or low attitude in coordination, lack of facilities and follow-up from Kebele and education office.

In describing the IFAE policy alongside with the contemporary practices and experiences, the participants reveal that, the policy is fully-fledged in leading the program. In order to put the policy into practices, strategy developed, and adapted at local level. To run the program of IFEA, the participants said schooling or place for learning or training centers are not accessible though there are schools at around. Some schools have program of IFEA under their leadership; however, theway of handling is with less commitment and coordination among the sectors. It can be said that adult attend the program but majority might be unable to use the literacy skills in their daily life (for example majority are not able to have the required knowledge and skills to join grade 4 in the regular school) and may be relapsed into nonliterate category(cannot have consistent reading, writing and computational skills). One can see in most of the training centers enrollmentis conducted at the beginning but very few adult learners complete their learning, since the majority drop the program. The interview result of the heads and FGD participants has been confirmed by samples of data at different time obtained from the document analysis as shown below in Figure 1.

Figure 1 indicates that the trendof adult education development in the year 2013 to 2016 seems growing, particularly for males than females. On the other hand, from 2016 to 2017, there was a drastic change or a complete decline in the number of both male and female learners. The reason might be no participants of adult 


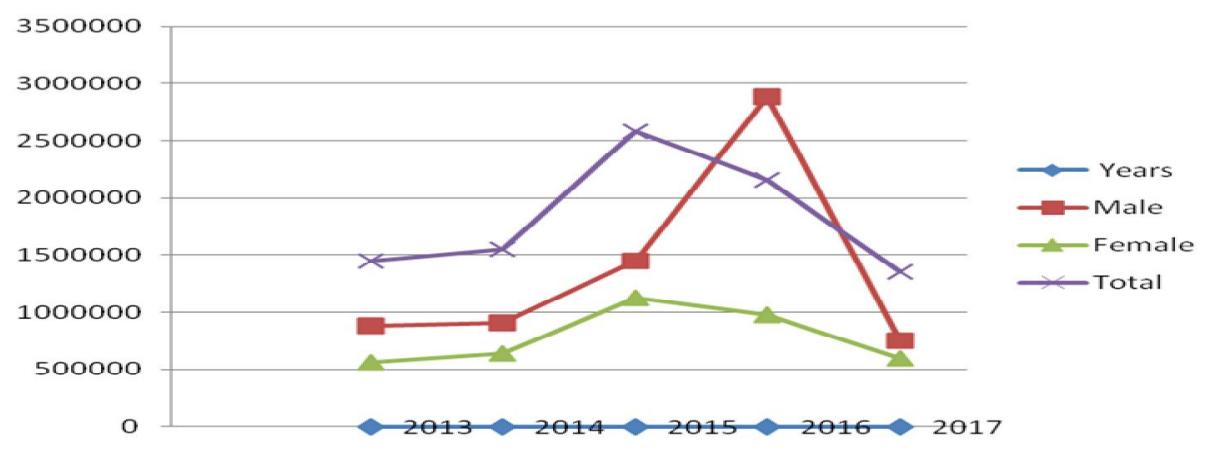

\begin{tabular}{cccc}
\hline Year & Male & Female & Total \\
\hline 2013 & 883183 & 559734 & 1442917 \\
2014 & 907938 & 640568 & 1548506 \\
2015 & 1448509 & 1129385 & 2577894 \\
2016 & 2882861 & 978795 & 3861656 \\
2017 & 750805 & 599155 & 1349960
\end{tabular}

Figure 1. IFAE trend in Oromiya. Source: Annual abstract (2017). Oromia National Regional State.

learners attending literacy, or the majority has been trained, or the participant might not like to come to the training centers. As the usual characteristic of adult program, attendants might drop the program. It can also be said, the reason for a decline in the year 2016 to 2017 could be lack of commitments in mobilizing the community from the side of district heads, kebele administration and facilitators, or it could be attributed to low motivation of adult learners' associated to political instability.

In this study, next to the regional deputy bureau head, zones and districts bureau heads, experts were also interviewed. The experts who were at regional level involve in curriculum design for primary, secondary, and adult education program. Their contribution has an impact onthe implementation of IFAE. They play role in preparing guiding documents such as flowcharts, learners' textbooks, teachers guide and other supportive learning materials.

The inquirer asked about their role in the practices of IFAE. Some of the FGD members said:

...we produced fellow chart and textbooks in collaboration with zones experts. In fact, for adult education we did not prepare additional teaching and learning materials like flyers, posters, pictures, short stories, and magazine, newsletters, which helps for effective implementation of IFAE. We are not exerting our maximum effort to facilitatehuman, materials and financial resources supporting Zonal, District, Kebele level education and training centers /schools levels (FGD2, expert, 2017).
Experts are the key player, in the process of implementing education policy and strategies. However, the FGD participants are not vibrant to support the IFAE program. The experts could have supported the program by producing easily portable and laically available materials that can facilitate the embodied literacy. Print materials such as flyers, short stories, newsletters, picturesetc.contribute much to keep the literacy skills upto-date.From experience where there is a problem, there is also research. The experts have no much concern to conduct research that can solve problems of adult learning. Moreover, implementation of a program needs involvements of divers sector, strong effort, and commitment. Experts at regional and districts level shall implement the agreement made at national level. In this regards, the participants did not have the experiences of working in collaborationwith agriculture, health and business sectors as per the strategic document.

There are surplus reasons why access to a large number of adults in the region does not receive adequate attention. Below are just some of the factors driving a lack of access to adult education.

Lack of equipped training centers: Many of the poorest local, rural, and urban kebeles in the region do not have access to adequate financial resources necessary to establish appropriate training center for adult education program. The government has given much emphasis to the child education. Community mobilization, awareness creation and motivation mostly focus on child education. As narrated above, the training IFAE is given not only at some formal schools but under shade, at religious institutions, and household level which might contributed 
for the demotivation of adult learners attracted to attend program. Providing training materials along with recruiting and training facilitators cost money, and the allocated financial fellow from formal school budget generally is not sufficient to establish an education system for adult learners. Moreover, the program has involved less number of female participants compared to their male counterpart (Figure 1). An adult learner attendance is not moving forward because of different reasons added to lack of attractive learning and training environment that has contributed lack of access to adult education.

\section{IFAE structure}

IFAE is structured under the MOE as coordinating office. It is important to consider the structure of the body in terms of fundamental levels of the organization that increase the simplicity or complexity IFAE to function. The structural organization and cooperation signed among sectors to share responsibility in relation to the implementation seems weak. The sign made among sectors such as MoE, Ministry of Agriculture, Ministry of health, Women affaire frozen without showing synergy in implementation. The sectors did not plan together except they sitdown for the signing ceremony since 2008.

In response to the issue of structure of IFAE, the deputy bureau head said that:

...the structure of IFAE was covered by the formal education structure. In running the program, there are different approaches from region to regions; in Oromiya for example we assigned a single director at regional level, at zonal and district level coordinators without authority in running human, material and financial resources. Others, establishes the office at process owner's level or run by case team or single focal person. There are diverse approach and structures for a single program. In this case, none of the structures have made the program effective (Deputy head, 2017).

The strategy has indicated that IFAE was supposed to run by a board composed of different sectors. However, in the current situation, the program is affiliated to the education sector with no collaborationwith other sectors. To this end, the experts were asked about the extent of local level sectors involvement, coordination, and planning to implement the program. In response to the question, one of the participants said,

The sectors are voluntarily involved to support the community; there is no one there accountable for the program. For example, the education sector at district level employ literacy facilitator to hold and run the program based on the adult learners textbook but other sectors involve development agents (health and agriculture extension workers) to train adult learners on their own training packages. In this regard, the multi--sectoral model did not function properly. No one monitors and reports the activities in time. For example, if the health sector or agriculture sector is not willing to run the program, no one enforces to conduct the program (Experts, 2017).

The experts were also asked to respond question like "To make adult education fit to the needs of adults, what should be done with it?" the participants gave the following response:

Initially, the emphases given to the program from the top management to the kebele level were low. The focus was to reach a large number of school-age children instead. However, recently access to primary school is almost achieved. The previous trend should not continue, facilitators and expert preparation has to function in the same way we prepare and run primary schools. On top of this, a proper structure must be established down to the district level to make the program more effective. The fulfillment of human, material and financial resources shall be improved to run the program in a more effective way (Experts, 2017).

The participant seems cognizant of the challenges of the program, but unable to respond proactively to the situation, which cannot be attributed to other factors. Particularly, the leadership quality for such fragmented activity has a significant impact on the program. The low emphasis given from the head easily moved to the actual implementers at the grassroots level. If the program cannot function with the right structure, with specified duties and responsibility, the local implementer cannot have clear direction in terms of planning, organizing, running activities, and reporting reliable results.

Apart from preparing the necessary curriculum materials for adult learners, identifying quality contents in terms of its relevance to the needs of the learners is the main duties of the experts. To this end, the experts were asked about the relevance and quality of the curriculum, one of the experts said,

...the contents in the textbooks were different for urban and rural but set with clear concepts explanations and activities, which can help adult learners best learn. However, we could not write additional learning materials other than textbooks. In relation to the curriculum, the region did not design competency-based curricula like non-formal vocation training that 
could better improve the skills of adult learners and quality of education at the level. We the experts have made effort to develop functional contents with a pilot testing whether it fits or not to the interest and needs of adult learners. In the current situation, we do not have clearly structured adult education program. As experts, we believe that the presence of a clear structure can minimize the problems and improve the quality of adult education in particular. The involvement of others cooperating sectors in the curriculum preparation was not visible. We could not solve the integration and coordination problems as it was planned. Utilizing professional classroom teachers or facilitators with adult education background for the curricula contents development was not made. Apart from these training facilitators on the textbook methodology was not done (Expert, 2017).

The experts further noted that,

... in future, it is important to establish independent institutions responsible to manage the program if there is need to reach adults with diverse needs (gender, location, and social class). The discussants forwarded that they expect the program to get attention at all levels to implement the policy designed. The authorities at different levels have to make strong intervention and show strong political commitment that can support the implementation at kebele level (FGD2, 2017).

The discussant above in their responses said that the ongoing practices of the program were challenged by lack of right structure, follow up, low emphases given from government. Besides, learning materials development process and cooperation among sectors were barriers to effectively implement IFAE. The essence of integration in writing the curriculum and scarcity of resource like qualified facilitators, to run the program and mode of delivering of the program as per the guideline has failed because, there was no visible structural integration of sectors. Writing curricula was not agreed among the sectors. After its development, the contents of the textbooks were not shared among education, agriculture, health, and business sectors. Moreover, the facilitators were not trained in relevant curricula. As a result, they could not properly handle the program in an integrated manner.

Responsibility and power sharing: Organizational structure is a way responsibility and powers are allocated, and work procedures are carried out. Organized structure is important for measuring or monitoring newly emerging program like IFAE. It helps to collect feedback and correct errors on time. In the IFAE program, there is no policy that clarifies who is responsible for what activities of the program. The nominal structure of the program is attached to the education sector by default. There is no horizontal communication or relationship among the different sectors supposed to run the program. The existing structure at coordinator level is integrated into the education sector, which has no power but run IFAE program under the umbrella of formal education. Other sectors such as agriculture, health, and business sectors are supposed to run adult education but they do not have adult education structure and ready to shoulder responsibility. As indicated above, IFAE seems to lack efficient and effective structure that could have helped quicker responses to adult education problems, increased unity of functions, and create alignment among the different institution to run the program.

\section{IFAE coordination}

In our education sector, experiences have shown a topdown approach to dominated the system where policy, strategy, guidelines are prepared at national. In a similar way, the coordination is follow top-down principle. Things are decided at the regional, zonal and district level and disseminated to kebeles, schools, and training centers. Co-ordination among sectors was not visible that is supposed to provide unity of action in the process of providing the right training to the adult learners. In this connection, IFAE has no special approach though adult training needs a different approach from children teaching. The coordination among sectors in the horizontal relationship is weak and the vertical relationship function is limited within the education sector. Referring to the issue of coordination the bureau head stated the following:

...adult education leaders or coordinators at different levels are not assigned on merit-based, as it is widely known. With regard to decentralization issues, the leadership could have been given with power to carry out responsibilities. In the leadership position, prevailing in the regional state political assignment had a lion's share. However, sometimes, at positions where professional expertise is required, a political assignment cannot lead to success. Success cannot be obtained easily unless free assignment is dealt with in full accord. Otherwise, it will boil down the quality of leadership. The assigned leader must be a man of merit who can largely accomplish the curricula, training and planning tasks with commitment. Moreover, each sector that is supposed to work on adult education 
must be empowered to act without political pressure (bureau head, March 2017).

The researcher has presented issues of adult learners' engagement.

With respect to follow-up, a keen effort was not made at all levels, to curb the weakness seen in the program. Until now, no evidence can prove us the number of adult learners continues to stay with up-to-date knowledge and skills gained during their training.

The participants of FGD have suggested the following points to improve IFAE program coordination.

At higher-level, universities and colleges at around should support the program by providing professionals, materials and financial aspects. It is also important to revisit the integration of sectors strategies and the sectors that were not yet taken the real responsibilities should be committed and ready to be involved in the program of adult education. Obviously, future employment and its expansion in the region are more attached to private sectors. Integration of IFAE with NGOs and private sectors is also important. It is necessary to create decent and remunerative jobs at the district level so that adult learners, particularly young adults who completed round 1 and 2 join the opportunities (FGD, expert, 2017).

From the assertions above, though there is readiness from the experts' side in implementing the program, more focus is still on formal school coordination and IFAE lacks follows up. The regional state in its coordination shall consider writing learning materials, which can increase reading and writing skills of adult learners. From the above citation, the main activities of the program are situated in the education sector only dropping other important sectors like health and agriculture.

Moreover, the other important implementer of IFAE was school committee which does have voice in improving the schools, adult training centers and community coordination. The FGD participants at school were briefed about their role in the community regarding coordination. The first question was to address how Parent Teacher Association (PTA) is coordinating the school to implement the IFAE training policy. To serve in the current position, they did not attend any PSTA training in a short term or long- term training for capacity building. The Kebele head and chairman of the school PTA said:

We write a plan with the school administrators to implement the school improvement program packages, make active involvement, and follow- up. But we did not start to organize. We also mobilize kebele residents to cover some activities like planting the tree, soil protection using trussing, and providing little financial support (FGD, PTA, 2017).

Other speakers from the group said that the school and surrounding community work together. For example, PTA is responsible to create a conducive learning environment and mobilize adults to join training centers; they call meetings, open discussion and convince parents on the importance of educating people. However, when asked about the number of centers, and attended the program including the school, every one taking part in the FGD kept silent. They said, currently, we do not have in terms of a figure but we give awareness and orientation when gathering for other purposes.

The discussants further said:

"We have not started with all our efforts, gave more attention to formal education but we offer little orientation to the importance of adult education. We attempted to orient about IFAE program during mobilization of farmers for soil protection using land terracing "DagaaLafaa." However, as to the registration and attendance, though many of them registered to start the program, three to four participants come to the program regularly. It is one of our responsibilities to support the program, he said. We made no strong follow-up in collaboration with responsible sectors expected to run the program. The task is not only given to the education sector, but also other offices such as agriculture, health, women and children affair, and business firms. To implement the policy at the grassroots level, school leadership has to give many emphases following school improvement program packages and applying a participatory approach to work with the community (FGD2, PSTA, March 2017).'

The participants reported that the issue of coordination with the right plan to mobilize adults who cannot read and write could not get much attention at all levels. The coordination from the top, sectors coordination, and kebele level integration is very weak. They confirmed that for some IFAE program may not even secondary to formal education at all levels.

Coordination among the different sectors could have involved planningand integrating the various activities designed for the program through mutual discussion and exchange of ideas. Coordinating includes organizing, and staffing, because it specifies who will be a staff and its rational placement. However, the coordination of IFAE program is limited only to simple orientation. The PSAT in this connection did not carry out their major responsibility, 
which is mobilizing human, material, and finance for the success of the program. The management of adult education requires the right personnel in various positions needed with the right type of education and skills so that there are right men on the right job. In thisschool or adult training center, giving orders to their job, instructions, and guidance to the facilitators or teachers is served with no harmony between the adult learners or the community and people supposed to run the program using proper coordination.

Lack of effective leadership: In this study, adult education program or IFAE involved poor leadership, because, the leaders found at different levels of the education sector are not able to share time in supporting this way of working. This applies that adult education program leaders are not seeking out opportunities to work with others; and recognizing staff involved in coordinated work; ensuring that resources (human, materials and finance) and time are available. The leadership is influenced by external and political pressures, which had an impact on the successful implementation of the program. The insignificant support of local authorities and their attitude towards IFAE program could not raise the participation of adult learners and increase commitment of facilitators. In this regard, the leadership practices cannot be taken for granted that could not be continually worked. As a result, the program could not involve a significant number of participants yearly and make coordinated activity for effective implementation of IFAE. To ensure the coordinated activity is successful, leaders need to make sure that sufficient resources support it. Moreover, the leaders should avoid their laissez-faire style and need to assist participants by ensuring joint activities is given priority, integrated into a wider system of their performance, and linked to budgetary allocations.

The leadership style must display a positive attitude to work well as a team and develop a sense of shared commitment among the different sectors. The participants need to establish working relationships based on mutual support and trust, acknowledging their differences, and share information openly for the benefit of IFAE participants.

\section{Capability or ability of facilitators}

Teaching in adult class is very much complex and governed by different laws such as andpedagogical, psychological, content relevance to the needs and logical move affecting each lesson. The complexity ofteaching necessitates capability or ability of facilitators. For example, ability to identify facts about adults behaviors to convince or persuade on the importance of the program , understanding and managing adults' behavior, ability to create alternative approach to simplify learning, organize learning, ideas and thoughts when making a verbal or written presentation.

In this study, the experts are very much concerned in the selection of facilitators. They indicated that the selection shall be based on maturity levels as young adult, physically strong or fit, and psychologically ready to shoulder classroom responsibilities and handling adult learners' classroom behavior. Majority of the facilitators involved in the program are of age between 18 and 23. The participants of FGD have said,

Majority of the facilitators are at early completion of grade 10, especially at the onset of adolescence. They usually give less attention towards the teaching profession, that makes the selection of facilitators most difficult. They complete grade 10 and join facilitation or teaching. Some of them attend only two to three days training, and when they become teachers or facilitators, they are still in need of guidance services from coordinators. They are challenged to guide learners since they are not matured enough to shoulder responsibility and satisfy the needs of adults (FGD, expert, 2017).

It could be noted that the physical and psychological aspect of the facilitators shall be taken into account when to join the program. Teaching and guiding adult learners need life experiences that can be shared with them. The recruitment of adult education facilitators, followed by effective and periodical on job training system is mandatory. To minimize the problem of IFAE, alternative directions set by the bureau head and experts are stated as follows:

The policy option for the selection of teacher'sfacilitators training at all levels can be done during elementary school time or it can be also carried out at secondary schools at grade 9 and10. Assessing interest and attitudes at early grade can simplify the problems that may happen when joining the profession. Usually, teachers remain effective by staying long years and internalizing the profession before coming to practical teaching. Without interest and positive attitude toward the profession, the rational employment cannot bring change (Bureau head, 2017).

The other option is to strengthen Continuous Professional Development (CPD) program, the head said. The CPD program has to be introduced for the change of status or levels, salary scale and accepted as a professional obligation at all levels for every teachers or facilitator. The salary increment or remuneration has to go in line with additional knowledge and skills he/ she gained, the bureau head said. 
Moreover, like any other profession to check teachers' progress in their skills and improve the quality of their teaching, they should sit for the professional exams periodically. (Bureau head, January 2017).

In fact, Oromiya does not train facilitators in IFAE curriculum. In all IFAE centers facilitators are largely those that have been trained in formal Teacher Training Colleges (TTCs). Such facilitators, having been trained for formal schools may find it challenging teaching in IFAEcenters. When they are assigned as afacilitator at the centers, theyusually employ teaching methodologies that they learnt at TTCs, which are not appropriate for IFAE and influence implementation of the curriculum.

Apart from these, both the head and experts said fulfilling materials and facilities to improve teaching and learning, the government entities work strongly at the local level in organizing, and coordinating the program. Facilitators' salary is the other key factor that does have impact in the proper implementation of the program. In order to keep facilitators stay longer in their job, the government improves salary,open educational opportunity, and recognize them as teachers contributing to the development of education in the region.

Lack of skilled facilitator: A key quality of a facilitator is to have a right attitude which is open to help adult learners discover his/her potential to address the needs with existing resources. This requires patience, and a commitment to see something through. It also requires respect of the individuals regardless of their background and belief. Developing facilitation skills through relevant training may take long time. After several practices, people involved in facilitation become confident in their skill. The other methods, which can develop the skill of facilitators, could be spending time with more experienced facilitators. The possible teaching quality of a facilitator can be described in terms of knowledge, attitude, and skills he/she acquired during training. In his / her attitude, a facilitator shall have compassion regardless of gender, age, and socio- economic background. He/she has to exhibit knowledge of understanding the subject matter and understanding of how to use different planning tools. Trained facilitators are expected to use different teaching methods, assessment technique, classroom management, and reaching learners with learning difficulties. The purpose of using all this instructional input is to address the needs and emotional feeling of adult learners. The skill and ability to summarize others' ideas and ability to ensure group participation among adult learners are some important quality of facilitators. However, as one can observe from the above analysis, the employed facilitators do not have plans to stay more in the profession.

The issue of salary is one of the challenges in implementing IFAE program. It could be difficult to decide whether to pay sufficient salary to facilitators or expect them to give their time voluntarily. Each context will require a slightly different response. There are few examples that facilitators at a different locality, give voluntarily serves assuming that the service has a certain value in competition for any vacant position and opportunity for further education. In this regard, in addition to government support, the local community shall think of ways they can support their facilitators financially. Facilitators are key to IFAE success because having highly motivated and enthusiastic facilitators who feel valued and supported can make a huge difference to the whole program.

\section{Planning as a challenge}

At zonal and district levels, the bureau heads expected to have fresh and reliable informationor data about program running under their leadership than the higher officials. In this regard, the researcher presented question-related to the status of IFAE in East Shawa Zone and Adama District. The discussants replied:

The coverage is a large number on a sheet of paper in the form of reports. However, extensive work was not done, and the distribution of training centers to remote localities is not effective. For instance, learners at the city have more access than rural areas forthe training. Creating a learning opportunity for those who quitted farming is very hard in the rural vicinities. In Adama Town itself, attending literacy learning is hard because the participants have an economic problem. Primary schools, in some places, are inaccessible to adult learners. Since some of the schools are situated far away from the community setting, the facilitators in many places are forced to use private household homes with the scarcity of materials like blackboard, chairs, and tables. Because of lack of knowledge about the characteristics of adults, in some training center mixing children and adults to attend in the same class and the same lesson becomes familiar. The children and parents sit together to learn lessons in adult class (Case 4, bureau head 2017).

The heads narrated IFAE implementation under his leadershipsaying that there is difference between reports and reality on the ground. The report is usually based on the data during registration time. Mostly, the final report does not correspond with the beginning data because of the characteristics of adult education. The problem of data variation may be associated with lack of proper panning, periodical supervision and reports. The head 
also reveal that creating learning opportunities at school level is found to be difficult because of distance. Some training centers are adjusted at private householdsituation where there are no facilities and difficult to address the academicand psychological needs of adults. Besides, the facilitators' motivation in such a class could sometimes depend on the commitment and social attachment with family members particularly the husbands who has usually an authority. The rural experience shows that the home has no reserved class for the training, but the same room used for different purposes such as cooking, sleeping, keeping cattle and rearing children.

Figure 2 shows that there is ahuge difference between what has been planned and executed at different training center.

As can be observed in Figure 2, centers such as private home and shades have a big number of plan but a very small number of participation accomplishments. The data showthatwhen the learning environment is not attractive like in schools and training centersadultsare not initiated to attend the program. At the school level, training accomplishments is about $45.62 \%$ of the plan, where as in other training centers it is below $45.62 \%$, which shows schools are more attractive for the adult learners. Adults learn informally many things from the school compounds than training centers arranged under shad or private homes.

Lack of capability of planning is not limited to the selection of the right place for learning but also having a concrete plan to mobilize registered adult for the training. As can be witnessed, at planning stage the facilitators and Kebele administration effort to sort out people ready to attend the program seems remarkable. However, the skill of attracting the adults to the training center or retaining them to stay for about three months or more was found a challenge.

Lack of visionary leaders: A visionary leaders use a strategic planning that can inspire and motivate coordinators and facilitators subordinate to his or /her leadership so as to achieve the goal of the organization. In the process of implementing a program, a strategic leader can minimize destruction that could happen in terms of resource utilization (human, material and financial). As can be observed in the above analysis, the regional government has no clear planning set up to reach the 9 million illiterate adult people. The leaders at different levels running the program do not have a system that could help them to utilize the secured resources available. The leaders have a great plan on a paper putting high enrollment number (Figure 2); however, they execute less than $25 \%$ at all training centers. In fact, lack of funding segment may affect potential leaders to come. Nevertheless, focusing on the characteristics of adult and non-formal education a leader must be flexible to see what is working and what is not working in the strategy and make adjustments accordingly. In this regard, researchers and government its self has repeatedly reported that the multi-sectoral model has failed because of lack of commitment at all levels, but the leaders in the area were not willing to give their ear for listening and abilities to improve the program.

\section{Refusal to take shared responsibilities/attitude}

Participants at regional, zone, and district level said, major of emphasis was given to formal education than IFAE in terms of planning finance, human, and materials fulfillment. At the school level, one of the participants of Parent Students Teachers Association(PSTA) members said, the government has set good strategy, and guide for adult education but lagged behind to put them into practices. The other participant also said,

..., the Zone and District education bureau are not willing to include the checklist that could have been used to assess the program. The politically assigned municipality mayors and kebele administrators are very busy with their regular office duty, not motivated to make follow up, and involve themselves in coordination. The facilitator assigned from education sector teaches all chapters that could have been facilitated by other extension workers. Moreover, low salary associated to low motivation of facilitators is themajor factors contributed to low performance. In addition, low attitude of adult learners, which has been observed by their poor attendance, have made the program ineffective. The participant said,all of us the learners, committee running the program, and the facilitators had the feeling of hopelessness because, the program is not getting attention from sectors responsible and expected to run the program (FGD2, January 2017).

The participant affirmed that facilitators have sometimes an additional job, such as teaching primary school children, visiting families of school dropouts, and working at kebele offices. At some center, the facilitators handle over 30 participants registered in around I and II. Some of the facilitators are satisfied in teaching adults and would like to stay in the profession, but majority use teaching as a bridge to move to other professions. In order to improve the attitude of adult learners, people in position, and facilitators in the program shall focus on how tocreateconducive learning environment and motivating adult learners both inside the classroom, and visiting their home is important. Regarding salary the government shall revise the scale that correspond their living. It is also noted that rigorous revision has to be made in order to make to the textbook meaningful to them for both round I 


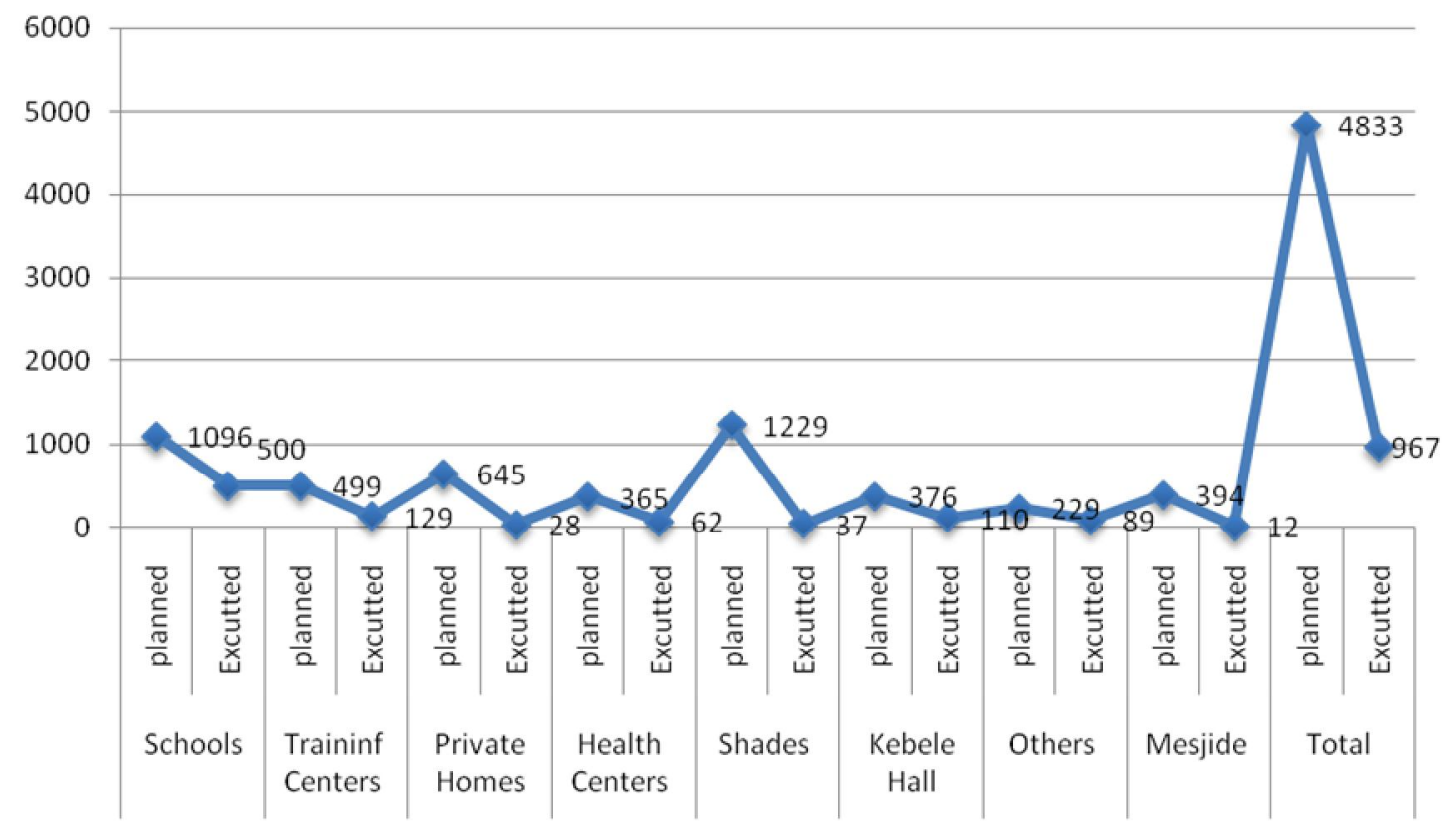

Figure 2. Distribution IFAE Centers in Arsi Zone in 2017. Source: Arsi Zone, Education office report (2017).

and II, he said (FGD2, January 2017).

From the above assertion, it can be argued that an individual who participates in adult learning may differ from one who does not in a number of ways. However, the changes in the lives of learners in terms of their improved livelihood, literacy and numeracy skills, and increased participation in community activities may lead to influence changes in attitudes of others. If such behavioral change has been observed as an effect of the training, the responsible individuals involved to run the program may be able to see the prospect of the program.

In looking upon facilitators, except some in towns, majority of the facilitators are assigned at their village to serve the program. They live and teach learners without going far away from their families. In fact, for some facilitators teaching at towns is found to be a challenge because of its high living standard. Adaption to a culture of town and the mismatch between medium of instruction is the other barrier to work effectively at some center. At some centers the learners use the national language (Amharic) and the facilitators mostly teach use the language of the textbook or local language. As a result, the facilitators assigned in towns are mostly forced to translate the local language (Afana Oromo) into the language spoken by the participants (Amharic). It indicates that the training of facilitators has defect, some of the facilitators could not be assigned in the centers where they are not fluent speakers and efficient in the training.

As can be understood from the case above, the implementation of IFAE at grassroots level lacks attention, coordination, and commitment. It shows that there is a gap between strategy set and the way of implementation. In most of the training centers, the literacy facilitators run the program from the education sector and teach all contents of the textbook that could have been taught by agriculture, health and business extension workers. As a result, the training program could not produce adults that have acquired the relevant skills and attitude to improve their livelihood.

Lack of positive mindset for adult education: It has been assumed that IFAE implementation was supposed to involve different stakeholder. Education sector by virtue of its position to the formal education has owned the program as one of the major stakeholders and involved in the implementation compared to other sectors. Leaders, expert, and coordinator in the sector including facilitators in the classroom are not possessed with a positive mindset or show positive attitude towards the program. It has been confirmed by this study that the job so far done is not likely show their active engaged and performance at a high level. It seems to show the stakeholders at different levels are not able to influence adult learners toward more positive, meaningful, and brighter life. An adult overall satisfaction in their lives is observed through engagement in learning and changing their life situation. The classroom scenario and people who received the training could not improve their livelihood. The result could have impact on the newly lineup adult learners for attending the program. In this regard, a positive mindset of all concerned stakeholder can more likely to overcome the failures.

In this context, the researcher did not utilize a measure to discuss the positive and negative attitude or mindset which can be described as limitation, however, the self- 
report from participants of this study has shown that there is a lack of positive mindset, low feelings of enthusiasm, and satisfaction towards adult education program. The participant mindset read us that the program of IFAE is not making life more enjoyable and attractive, encouraged self-development, dreams and aspirations. As a result, participants, coordinators, leaders in the area and facilitators are not great performers and encouraging others to join the program.

\section{DISCUSSION}

In this study, it was indicated that many of the implementation problems were associated with the access, structural, coordination problem, political commitment, and inability of implementers at different levels. To help the non-literate adults see a new and bright future, the sectors have notyet developed experiences of working together at the planning stage and organizing the IFAE program. The government of Oromiya shall direct its policy implementers to show commitment, ensureaccess to adult education, and create adequate educational opportunities at local level, particularly at kebele level.

Hoy and Miskel (1978:215) believe that "policies are not only formulated but also communicated, monitored and evaluated". In fact, Lindblom (1959:86) believes that a wise policymaker cannot expect all their policies to achieve a one-hundred percent success. Regardless of how good a policy may be, its implementation may introduce some element of imperfection. However, in this study, in the regional context, the implementation at the kebele level is being observed without the coordination of the sectors.

Adult education program recognized officially at national, regional and local level implemented with full of challenges. The integrated functional education could not help much and maintain traditional values such as building working together or "dabo" during the time of harvest or plowing land and seeding at different season. It has been observed in this study, that implementers are not able to know what they are expected to do. There was no communication or network among sectors, and there were inconsistencies of structure and data, capability problem at zones, districts, kebele and training centers or incompetent staff low political support, inadequate financial resources and lack of positive attitude of the implementers. As a result, the IFAE with its potential contribution to technological development and growth has failed to make any differences among adult community utilizing the program. These findings are consistent with Abeje (2017) who conducted a study on pastoralist area found that adult education is challenged by governance structure, funding, and lack of Integrated effort with other sectors. Van Horn and Van Meter (1977) which revealed that policy implementation fail because of lack of effective communication, capability problem, political support, inadequate financial resources, time constraints, and dispositional conflicts or reluctance of the assigned implementers to carry out their own assignments.

In this regard, Harris (2009) argues that the public has continuously perceived adult training as the path from school to the less academic situation. Harris further points out that the adult education program had poor results in terms of improving the living conditions of those individuals. This assertion has been confirmed by FGD conducted with adult education facilitators on May 45/2017 at Arsi University. In the current study, the program did not get much attention compared to formal education. They said that, the public is not ready and willing to attend the program because of lack of attention from all stakeholders.

The direction set to implement the program is a collaborative approach among sectors of education, agriculture, and health extension workers. The sectors are expected to play a greater role. However, the study reveals that only focal person at district education offices and the literacy facilitators at training centers make a follow up on the progress of the program. Indicating the importance of facilitators, Tolera et al. (2017) assert that teachers/facilitators in adult literacy learning programs are recognized as being vital to successful learning outcomes. Teachers and trainers play an important role in motivation and success of learners (Katiliute, 2005).

The study also notes about the financial resource constraint to cover salary, fulfilling learning facilities, and coordination among different sectors. This could be attributed to two cases, lack of enough budget in which adult education is mostly supported by the government and maybe miss management of the small budgetallotted by putting more emphasis and priority on formal education. On the other hand, the government body at local kebele does not have aid to support adult education program which makes the case acute. This is because the total volume of aid both from government and nongovernmental organizations made available to adult education is always too little and is tied only for political consummation. Consistent with this, Negash (2006) asserts that although a considerable portion of governments' budgets is made up of development aid, it is inconceivable that this external financial input could not lead to a sustained development. The aid is usually invested for formal education and few for democratization process but not to cover the expenses of the non-formal education or adult education.

The present study of IFAE employed qualitative approach, the sampling technique is purposive, and the sample size is not large enough to generalize. It can be concluded that the present adult and non-formal education implementation strategy is not at its preliminary stage because strategy, curriculum guides, focal person, and very few facilitators are in place. However, for all 
education bureau heads, adult education is not in their priority agenda may be because of the influence of formal education characteristics. As can be notched in this study, the practices are not in a good condition, the people are not discharging their responsibilities at all levels( regional, zonal, district and kebele levels). Moreover, the sectors are not interconnected at local level to support the effective implantation of IFEA. In fact, it was depicted in the national strategy that there is a need to implement demand-driven and workable Integrated Functional Adult Education program that facilitates and improves the literacy skills and the livelihood of adult learners. Nevertheless, the current model "multi-sectoral model" is challenged by lack of limited access, synergy among sectors, active structure, commitments, coordination and low attitude towards the program on the side of the responsible bodies to run the program. In this regards, the regional government shall take the lion share and responsibility to work on the dysfunction of IFAE that can be attributed to education leaders, experts, local kebele administrators, and facilitators. In general, since this is a qualitative research limited in size and variables, before dependable result is reached, researchers shall conduct further study by increasing study site, variables of study, the sample size and other necessary but missing from the current study.

\section{Conclusion}

The present study of IFAE employed qualitative approach, the sampling technique is purposive, and the sample size is not large enough and convenient to generalize. It can be concluded that the present adult and non-formal education implementation strategy is not at its preliminary stage because strategy, curriculum guides, focal person, and very few facilitators are in place. However, for all education bureau heads, adult education is not in their priority agenda. This may be because of the influence of formal education characteristics. As can be noted in this study, the practices are not in a good condition, the people are not discharging their responsibilities at all levels (regional, zonal, district and kebele levels). Moreover, the sectors are not interconnected at local level to support the effective implantation of IFEA. In fact, it was depicted in the national strategy that there is a need to implement demand-driven and workable Integrated Functional Adult Education program that facilitates and improves the literacy skills and the livelihood of adult learners. Nevertheless, the current model "multi-sectoral model" is challenged by lack of limited access, synergy among sectors, active structure, commitments, coordination. and low attitude towards the program on the side of the responsible bodies excepted to run the program. In this regards, the regional government shall take the lion share and responsibility to work on the dysfunction of IFAE that can be attributed to education leaders, experts, local kebele administrators, and facilitators. In general, since this study is a qualitative research covering limited sample size and variables, before dependable result is reached, researchers shall conduct further study by increasing study site or scope, variables of study, the sample size, and other necessary issues missing from the current study.

\section{REFERENCES}

Annual abstract (2017). Oromia national regional state annual abstract. Finfine: unpublished.

Chamebo, D. (2016). The contribution of integrated functional adult literacy to social capital development in adult learners: kirkossub city of Addis Ababa City. Addis Ababa University. Unpublished MA Thesis

Creswell, J. W. (2007). Qualitative inquiry \& research design, choosing among five approaches (2nd ed.). Thousand Oaks, California. Sage.

European Commission (2015). Improving policy and provision for adult learning in Europe Luxembourg: Retrieved 11 October 2017 from http://europa.eu.

Fanta, Y. (2005). The effect of the transition from an agrarian society to a knowledge-based society on technological literacy among Ethiopian immigrants in Israel. Unpublished doctoral dissertation: Tel-Aviv: TelAviv University.

Harris, R. (2009). The historical contribution of adult vocational education to social sustainability in Australia in UNEVOC 2007.

Hoy, W. K., and Miskel, C. G. (1978). Educational administration: theory, research, and practice. New York: Random House.

Katiliute, E. (2005). Issues of education policy implementation: differences in education stakeholders' attitudes. Institute of educational studies. Faculty of Social Sciences, Kaunas University of Technology, Kaunas, Lithuania.

Lindblom, C. (1959). The science of muddling through. Public Administration Review, 19: 78-88.

McGinn, N., and Street, S. (1982). The political rationality of resource allocation in Mexican public education. Comparative Education Review, 26(2): 178-198.

Mohammed, B. (2016). Implementation of functional adult literacy in Dodola Woreda, West Arsi zone, Oromia national regional state.Unpublished MA Thesis.

Negash, T. (2006). Education in Ethiopia: From crisis to the brink of collapse. Stockholm, Elanders Gotab ABOEB (Negash). Adult education report. Finfine, Oromiya Education Bureau, Ethiopia.

Sisay, A., and Yilfashewa, S. (2017). Integrated functional adult literacy: Existing practices and challenges in Eastern Ethiopia. International Journal of Education and Literacy Studies, 5(1): 86-97.

Tolera, R., Rogers, A., and Warkineh, T. Z. (2017). How do adults learn to read? communities of practice approach . Prospects, 46(3-4): 345-355

Van Horn, C. E., and Van Meter, D.S. (1977). The implementation of inter-governmental policy. Studies Review, 1, London: Stage Publications.

Welsh, T., and McGinn, N. (1999). Decentralization of education: why, when, what and how? Paris: UNESCO/ International Institute for Educational Planning.

Yin, R. K. (2011). Qualitative research from start to finish. The Guilford press, New York.

Yitayew, M. (2018). Implementation of integrated functional adult literacy program in metekel zone of mandura and pawi woredas. Addis Ababa University unpublished MA thesis.

Citation: Negassa, T. (2019). Challenges of the implementation of Integrated Functional Adult Education (IFAE) in Ethiopia: A case of Oromiya National Regional State. African Educational Research Journal, 7(3): 103-117. 